\section{Eventos em 2019}

No que refere a feiras, 2019 começou com a Expo Revestir, 10 a 13/03, uma promoção da ANFACER. Com base na qualidade dos lançamentos, o volume de negócios e o número de visitantes, o evento foi um sucesso. Entre 11 e 13/06 teremos a $\mathbf{1 0}^{\circ}$ Forn\&Cer, uma promoção da ASPACER que também promete.

Em relação aos eventos, nos dias 12 e 13/06 teremos o $8^{\circ}$ Congresso da Indústria de Revestimento Cerâmico, promovidos pela ASPACER. Este congresso prioriza a apresentação de trabalhos que tratem de temas atuais e que tenham aplicações práticas no setor cerâmico. O público-alvo são os profissionais que atuam na área industrial das empresas cerâmicas e na cadeia de fornecedores. Mais informações no site da ASPACER. Entre 04 e 07/08 teremos o $6^{\circ}$ Congresso Brasileiro de Cerâmica, uma promoção da Associação Brasileira de Cerâmica - ABC. Mais informações no site da $\mathrm{ABC}$.

Outros eventos, além dos mencionados acima, serão realizados. É importante estarem atentos.

Anselmo O. Boschi

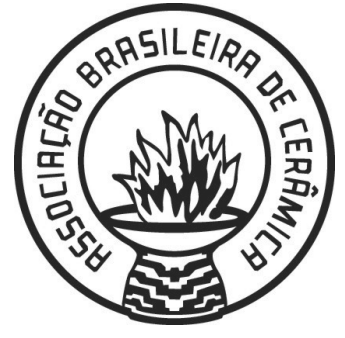

\section{Diretoria}

Presidente

Antonio Carlos de Camargo Instituto de Pesquisas Tecnológicas do Estado de São Paulo S/A-IPT

\section{Vice-Presidente}

Edmilson Ricelli dos Passos Elfusa Geral de Eletrofusão Ltda.

\section{Diretor Administrativo-Financeiro}

Juliana Marchi

Universidade Federal do $A B C$

Diretor de Publicações

Fernando Ortega dos Santos Centro Universitário FEI

Diretor de Assuntos Empresariais

Mauro Akerman

Akerman Desenvolvimento Profissional Ltda.

\section{Diretor de Assuntos Especiais}

Edgar Dutra Zanotto

Universidade Federal de São Carlos

\section{Diretor das Comissões Técnicas}

Ulisses Soares do Prado

Lining Representação, Consultoria e Projetos Ltda.

\section{Diretor de Comunicações}

Válquiria de Fátima Justo Escola Politécnica da Universidade de São Paulo

\section{Diretor de Eventos}

Samuel Marcio Toffoli

Escola Politécnica da USP 